\title{
Assessment of factors for the increase in the productivity of grain crops
}

\author{
Svetlana Petrova ${ }^{1}$, Danil Zyukin ${ }^{2}$ \\ Kursk State Agricultural Academy named after I.I. Ivanov, 70 K. Marx St., Kursk, 305021, Russian Federation
}

\begin{abstract}
Grain production is a strategic element of the agricultural and food complex in Russia, which predetermines its fundamental importance in food security. The task of the increase in the level of grain yields is still urgent, despite the full satisfaction of the needs of the domestic market of Russia due to the benefits from grain exports. The authors assess the influence of the intensification processes on yield level taking into account the elimination of the influence of scale factor. During the research such statistical methods as correlation-regression and cluster were used as analysis tools. The authors revealed a pattern that a higher level of production costs per 1 hectare of grain crops provided a correspondingly higher yield. In the context of total large grain-sowing companies with an area of crops from 4 to 11 thousand hectares, a relatively high elasticity of production costs was revealed (0.87), which was higher than in the group of medium-sized companies (from 2 to 4 thousand hectares) by 0,37 points. The scale factor had a significant influence on the intensification process and on the yield respectively. The model of the relationship between the size of cultivated areas and the yield of grain crops was qualitatively described by a parabola with a high degree of stochastic relationship. The maximum yield value was reached by a group of large grain-sowing companies with an area of crops from 5 to 10 thousand hectares, while in very large agricultural companies the yield was lower and was at the average level for the region.
\end{abstract}

\section{Introduction}

Grain crops are the basis of agricultural production in Russia. They present the basic group in crop and forage production. Grain crops are the main consumer product in the context of the food security of the country in an unfavorable global geopolitical situation [1].

Grain production is one of the few areas of national agriculture that not only fully covers the needs of the Russian domestic market, but also has a high export potential. Russian wheat occupies a leading position in the global market. However the transition to a higher level of efficiency is hindered by a number of reasons. One of them is the state of production and logistics infrastructure inappropriate to relevant tasks and needs [2]. The second fundamentally important aspect is crop instability in Russia. The key factor in this situation is to address the issue of the provision of the sustainability of yield level while reducing dependence on natural and climatic factors. Since in the main grain-producing regions of Russia, the plowed area sometimes reaches $80 \%$, due attention should be paid to the intensive factors in order to obtain a high and stable yield of grain crops [3].

The effectiveness of intensification largely depends on the organizational and production aspects, for example, on the size of business. Therefore, in order to assess the effectiveness and efficiency of intensification, it is important to ensure the elimination of the influence of the scale factor.

\section{Research methodology}

The research is based on the data of statistical analysis, the main tools of which are correlation-regression and cluster methods. The correlation method toolkit includes the assessment of the partial correlation between indicators, where the yield level is the effective and the studied factor signs are regressors. The most significant organizational and production factors that determine the value of the yield of agricultural enterprises are the level of concentration of resources and the degree of intensification of production. The correlation is assessed within the entire array of agricultural companies of the Kursk region, engaged in the cultivation of grain crops and in the context of enlarged clusters formed by the value of regressor (factor attribute). The grouping method is used to form such clusters. To ensure the reliability of the data, the statistical regularity will be confirmed with various methods of grouping in accordance with the existing grouping of the size of grain production and statistical approaches. The analysis was carried out within the framework of the formed clusters according to the primary factor attribute in order to eliminate the influence of the size factor of agricultural production in the assessment of the

\footnotetext{
* Corresponding author: nightingale46@rambler.ru
} 
relationship between the yield of grain crops and the level of intensification, expressed by the value of costs per 1 ha of cereal crops.

\section{Results and Discussion}

\subsection{Relationship and dependence of grain yield on scale effect of production}

Large crop business has a number of significant advantages over smaller businesses. This includes both available financial and labor resources and administrative support [4]. The presence of a representative technical and financial base allows providing more profitable cooperation with suppliers and buyers of grain both with resellers and with a direct contract with processing enterprises. At the same time, due to the geographical remoteness, even large Kursk grain-producing enterprises do not have an effective opportunity to engage in export. Nevertheless, the cooperation with large trading companies is still carried out at higher prices than with enterprises with small volumes of supplies. In the Kursk region, this pattern was fully preserved until 2014-2015. However, due to the changed market conditions, production and economic efficiency has become higher among agricultural companies with a cultivation area of 4 to 8 thousand hectares. Nevertheless, according to all production and economic indicators, large business corresponds to the average indicators for the region, while small enterprises with a grain area of less than 1 thousand hectares are characterized by the least efficiency and effectiveness of their activities. Therefore, there is a stable direct relationship between the level of yield and the size of the sown area. Comparing these 2 indicators for all agricultural companies of the region, a moderate correlation was obtained. With the enlargement of the intervals, the stochastic relationship becomes stronger, confirming the idea that there is a stable positive trend of increasing the yield of grain with the increase in the size of the sown areas under them in an agricultural enterprise. In order to confirm the consistency of this observation, several approaches were used to form the intervals of groups of agricultural companies by the size of grain crops. In the first approach, the groups were formed taking into account a geometric progression in a step, which allowed scale effect that had a non-linear character in the form of an exponential. This pattern is used for economic factors of production by virtue of the law of limiting decreasing sequence.

Based on this, the authors suppose that the increase in crops per conditional area for agricultural producers significantly different in size of arable land will give disproportionate organizational advantages.

In accordance with this statistical approach to the grouping of agricultural companies, it was revealed that there was a regularity in the growth of yield as the size of the grain-sowing company was enlarged to the level of 8 thousand hectares. In the future, in the largest agricultural companies, the grain yield indicator begins to decline. At the same time, it is at the average level for the region, exceeding the indicators of groups with a grain sowing area of less than 2 thousand hectares (Table 1).

Table 1. The interrelation between the yield and the size of grain crops in the groups of agricultural companies formed on the basis of a geometric progression

\begin{tabular}{|c|c|c|c|}
\hline $\begin{array}{c}\text { Group } \\
\text { interval, } \\
\text { thousand ha }\end{array}$ & $\begin{array}{c}\text { Average area of one } \\
\text { agricultural company, } \\
\text { thousand hectares }\end{array}$ & $\begin{array}{c}\text { Number of } \\
\text { companies }\end{array}$ & $\begin{array}{c}\text { Grain } \\
\text { yield, kg } \\
\text { / ha }\end{array}$ \\
\hline More than 16 & 35,59 & 10 & 52,9 \\
\hline from 8 to 16 & 12,30 & 9 & 53,3 \\
\hline from 4 to 8 & 5,43 & 19 & 63,2 \\
\hline from 2 to 4 & 2,72 & 44 & 54,1 \\
\hline from 1 to 2 & 1,48 & 33 & 49,2 \\
\hline from 0,5 to 1 & 0,79 & 35 & 41,6 \\
\hline $\begin{array}{c}\text { from 0,250 to } \\
\text { 0,5 }\end{array}$ & 0,36 & 15 & 36,9 \\
\hline $\begin{array}{c}\text { Less than } \\
\text { 0,25 }\end{array}$ & 0,12 & 186 & 33,8 \\
\hline $\begin{array}{c}\text { Value for the } \\
\text { Kursk region }\end{array}$ & 4,16 & 21 & 53,7 \\
\hline
\end{tabular}

This regularity is qualitatively described by a parabolic type model, where the average yield in the group (OY axis in Figure 1) acts as a resultant feature and the average value of cereal crops in the group in one company ( $\mathrm{OX}$ axis in Figure 1) is the regressor. The determination coefficient characterizes that the variation of the effective trait is described by the regressor over $50 \%$, which indicates a very close stochastic relationship (the correlation coefficient is over 0.7 ).

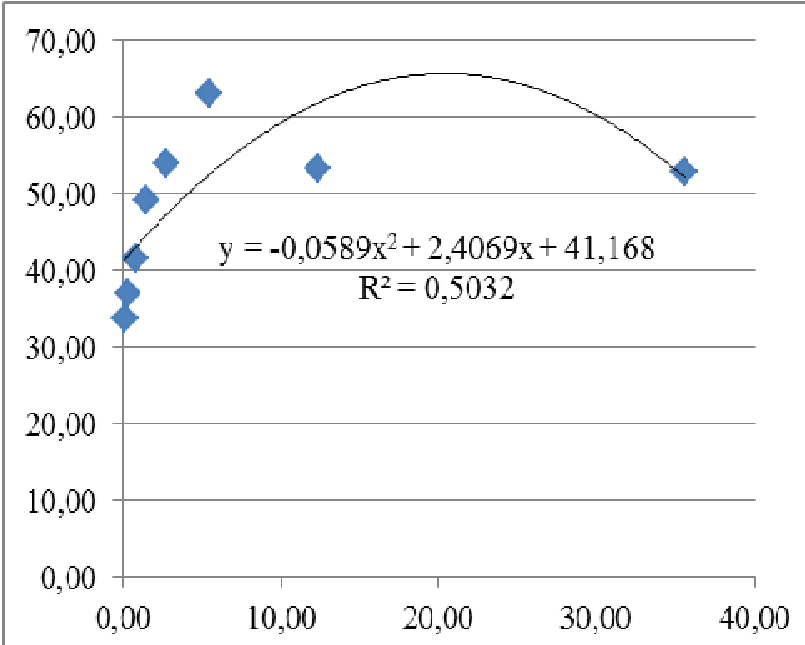

Figure 1. Approximation of the parabolic model of the interrelation between the group indicators of grain yield and the sown area of grain formed on the basis of a geometric progression

The alternative option for the construction of group intervals is to use an arithmetic progression, while the number of groups remains similar to the approach using a geometric progression. There is a tendency for the increase in the yield of grain crops with an increase in the regressor to the level of 61.2-61.6 c / ha in groups with an area of grain crops from 4 to 7 thousand hectares and from 7 to 11 thousand hectares. In the future, the yield begins to decline, but it remains above the average 
for the region, except for the group of the largest grainsowing companies with an area of crops over 22 thousand hectares (Table 2).

Table 2. The interrelation between the yield and the size of grain crops in the groups of agricultural companies formed on the basis of an arithmetic progression

\begin{tabular}{|c|c|c|c|}
\hline $\begin{array}{c}\text { Group } \\
\text { interval, } \\
\text { thousand ha }\end{array}$ & $\begin{array}{c}\text { Average area of one } \\
\text { agricultural company, } \\
\text { thousand hectares }\end{array}$ & $\begin{array}{c}\text { Number of } \\
\text { companies }\end{array}$ & $\begin{array}{c}\text { Grain } \\
\text { yield, kg } \\
\text { / ha }\end{array}$ \\
\hline More than 22 & 42,8 & 7 & 51,1 \\
\hline from 16 to 22 & 18,1 & 4 & 56,2 \\
\hline from 11 to 16 & 13,2 & 5 & 57,1 \\
\hline from 7 to 11 & 8,6 & 6 & 61,6 \\
\hline from 4 to 7 & 5,0 & 16 & 61,2 \\
\hline from 2 to 4 & 2,7 & 44 & 54,1 \\
\hline from 1 to 2 & 1,5 & 33 & 49,2 \\
\hline Less than 1 & 0,5 & 71 & 40,4 \\
\hline $\begin{array}{c}\text { Value for the } \\
\text { Kursk region }\end{array}$ & 4,16 & 186 & 53,7 \\
\hline
\end{tabular}

The interrelation of the factor attribute - the groupaverage value of grain crops in one company (OX axis in Figure 2) and grain yield (OY axis in Figure 2) is also reliably described by the parabolic model, although with a lesser degree of approximation than in the first grouping option.



Figure 2. Approximation of the parabolic model of the interrelation between the group indicators of grain yield and the sown area of grain, formed on the basis of an arithmetic progression

The use of a not a statistical approach to the grouping of agricultural organizations, but the approach in accordance with the existing in practice grouping of grain-growing farms according to the size of grain crops, forms a smaller number of groups, which allows more clear reflection of the parabolic model of the relationship of this factor with the level of productivity in modern economic conditions. The highest productivity was recorded in agricultural companies, the area of cultivation of grain crops which exceeded the average value for the region. It was also revealed that with the consolidation of grain production in excess of 10 thousand hectares, there was a decrease in yield. In agricultural companies of medium-sized crops of grain crops (from 1 to 5 thousand hectares), the yield indicator corresponded to the average regional value and in the largest companies the indicator was slightly lower (Table 3).

Table 3. The interrelation between the yield and the size of grain crops in 2019

\begin{tabular}{|c|c|c|c|}
\hline $\begin{array}{c}\text { Group } \\
\text { interval, } \\
\text { thousand ha }\end{array}$ & $\begin{array}{c}\text { Average area of one } \\
\text { agricultural } \\
\text { organization, thousand } \\
\text { hectares }\end{array}$ & $\begin{array}{c}\text { Number of } \\
\text { companies }\end{array}$ & $\begin{array}{c}\text { Grain } \\
\text { yield, kg } \\
\text { / ha }\end{array}$ \\
\hline More than 20 & 35,59 & 8 & 51,5 \\
\hline from 10 to 20 & 12,30 & 10 & 56,3 \\
\hline from 5 to 10 & 5,43 & 11 & 66,5 \\
\hline from 1 to 5 & 2,72 & 86 & 53,3 \\
\hline Less than 1 & 1,48 & 71 & 40,4 \\
\hline $\begin{array}{c}\text { Value for the } \\
\text { Kursk region }\end{array}$ & 4,16 & 186 & 53,7 \\
\hline
\end{tabular}

All approaches to the formation of groups made it possible to reveal a general tendency: with the increase in the area of grain crops, the yield also grows with a maximum in a group of agricultural organizations from 4 to 11 thousand hectares. In the future, the enlargement of production negatively affects the results: the yield in very large companies decreases. At the same time, the indicator of grain yield in small business is the lowest, which confirms the strong influence of the size factor. The relationship between the indicators at the qualitative level is approximated by a parabolic model, which reflects the inappropriateness of the policy of consolidation of the business engaged in the cultivation of grain crops.

\subsection{Formation of a set of data in order to study the effect of intensification taking into account the elimination of the effect of the size of grain crops as a factor}

In order to determine the influence of intensification of grain production on the results of activities, it is important to eliminate factors that may affect the accuracy and adequacy of the results. One of the most important organizational and production factors is the scale effect, which largely determines the capabilities and conditions and hence the efficiency of production. There is no doubt that the size of the grain sowing organization determines the features of the intensification process in crop production. Therefore, it is important to form a set of homogeneous data in order to solve the research problem.

Since the influence of factors is analyzed only in the context of the yield level, only this indicator will be used to compare the groups. The calculation results presented in Tables 1, 2, 3 clearly reflected the difference in the groups of grain-growing farms in terms of yield, depending on the size of the sown areas. The combination of groups or expansion of their intervals allows increasing the sample of agricultural companies for which statistical analysis will be carried out. It provides a higher representativeness and reliability. In the context of the conditions and results of 2019, we determined 2 sets of grain sowing companies for further analysis. The first group includes large agricultural companies with an area of grain crops from 4 to 11 
thousand hectares, showing the highest level of productivity. The second group is medium agricultural companies with a sown area for grain crops from 2 to 4 thousand hectares with an average level of productivity for the region. The analysis was not carried out among the largest grain-sowing companies since there was a significant variation in the sowing area and the specifics of the management and placement were stronger. It was also difficult to analyze intensification in small companies (with a grain sowing area of less than 2 thousand hectares), since financial resources in many cases were not enough to carry out a full intensification of the grain cultivation process, which was indicated by a significantly lower yield level in comparison with other groups.

\subsection{Influence of the degree of intensification of cultivation of grain crops on their productivity}

The process of intensification is one of the main factors ensuring the sustainability of crop yields. In the context of different countries of the world, which are in diverse and highly differentiated natural and climatic conditions, this becomes an element that affects food security [5].

In the context of quantitative accounting in the economy of plant growing, the intensification of production is expressed as an indicator of the value of costs per 1 ha of arable land. This indicator has increased several times over the past decade, but it is impossible to speak of a proportional qualitative improvement due to high inflation. At the same time, the situation has become much better and many grain-sowing companies have made a qualitative step forward, which is reflected in the level of yield. This very indicator is the most important criterion for the technological and production efficiency of the process of the cultivation of grain crops and determines not only the volume of product output per unit area, but also the quality of grain [6]. The comparison of changes in the level of productivity and costs per 1 ha of grain crops allows assessing the elasticity of the use of intensification in a certain set of companies. A power-law model allows obtaining a quantitative assessment of the level of elasticity of the factor use. The higher the degree parameter of the factor, the more elastic it is used.

In the context of large-scale crops of producers, the elasticity of use of costs in 2019 had a relatively high level of 0.8758 . Stochastic relationship in a nonlinear model of interaction between the yield of grain crops (the resultant sign, reflected along the OY axis in Figure 3 ) and production costs per hectare of grain crops (the regressor, reflected along the $\mathrm{OX}$ axis in Figure 3).

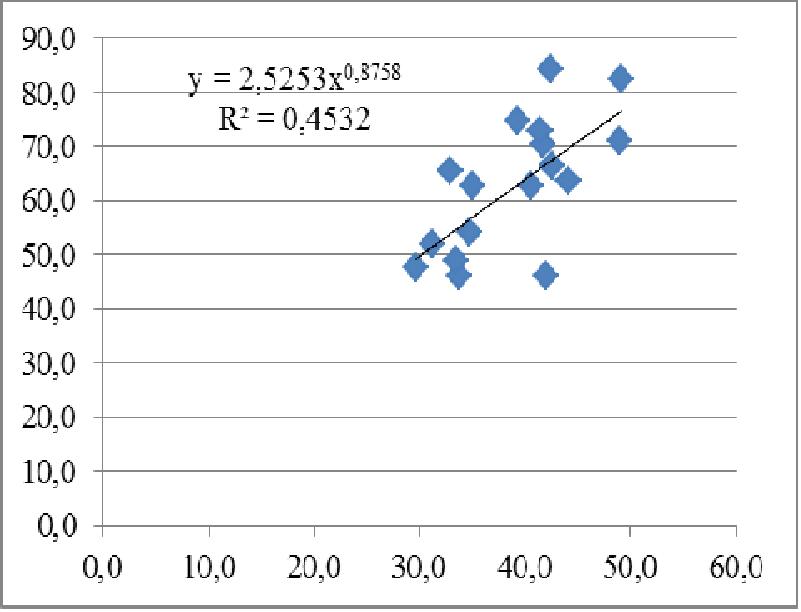

Figure 3. Approximation by a power-law model of the interrelation between the level of grain yield and the intensification of their cultivation in a group of largescale crops of grain producers

The results of the grouping by the level of costs per 1 hectare of grain crops among large grain-sowing companies prove the advantage of entities that conduct production more intensively. The limits of the beneficial use of intensification tools are shown: the group of agricultural companies with the highest costs per 1 hectare of grain crops has a comparable, but still lower level of productivity than the representatives with lower costs (Table 4).

Table 4. The interrelation between the yield and the level of intensification in the group of large sowings of grain agricultural companies in 2019

\begin{tabular}{|c|c|c|c|}
\hline $\begin{array}{c}\text { Group } \\
\text { interval, } \\
\text { thousand } \\
\text { rubles per 1 } \\
\text { ha of grain } \\
\text { crops }\end{array}$ & $\begin{array}{c}\text { Production costs } \\
\text { per 1 ha of grain } \\
\text { crops, thousand } \\
\text { rubles }\end{array}$ & $\begin{array}{c}\text { Number of } \\
\text { companies }\end{array}$ & $\begin{array}{c}\text { Grain } \\
\text { yield, } \\
\text { kg / ha }\end{array}$ \\
\hline More than 45 & 53,9 & 6 & 63,8 \\
\hline from 35 to 45 & 41,4 & 9 & 65,4 \\
\hline Less than 35 & 30,6 & 7 & 52,8 \\
\hline Group average & 41,3 & 22 & 61,3 \\
\hline
\end{tabular}

In the context of average grain crops by grain producers, the elasticity of production costs is significantly less than in the group of larger farms, although with a little closer stochastic relationship between the indicators (Figure 4). 


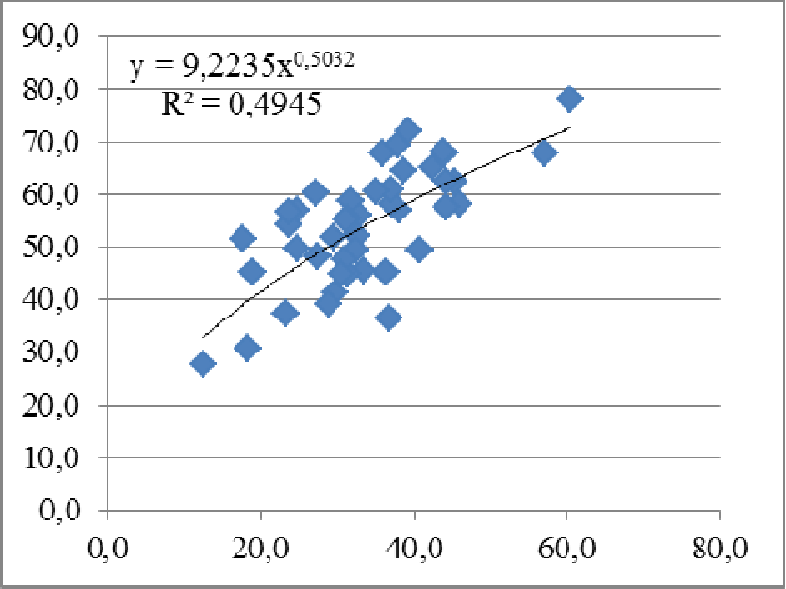

Figure 4. The approximation by a power-law model of the interrelation between the level of productivity of grain crops and the intensification of their cultivation in medium-sized crops of grain crops of grain producers

The grouping for this set of grain-sowing companies has a clear direct interrelation between the factors: the yield increases significantly with the increase in production costs from the lower group to the upper one. At the same time, the relative increase in yield as a percentage is lower than the production costs per 1 ha of grain crops, which determines the moderate elasticity of their use (Table 5).

Table 5. The interrelation between the yield and the level of intensification in the group of medium-sized crops of grain agricultural companies in 2019

\begin{tabular}{|c|c|c|c|}
\hline $\begin{array}{c}\text { Group } \\
\text { interval, } \\
\text { thousand } \\
\text { rubles per 1 ha } \\
\text { of grain crops }\end{array}$ & $\begin{array}{c}\text { Production costs } \\
\text { per 1 ha of grain } \\
\text { crops, thousand } \\
\text { rubles }\end{array}$ & $\begin{array}{c}\text { Number of } \\
\text { companies }\end{array}$ & $\begin{array}{c}\text { Grain } \\
\text { yield, kg / } \\
\text { ha }\end{array}$ \\
\hline More than 40 & 47,2 & 10 & 64,1 \\
\hline from 30 to 40 & 34,5 & 20 & 55,2 \\
\hline Less than 30 & 23,2 & 14 & 45,4 \\
\hline Group average & 33,8 & 44 & 54,1 \\
\hline
\end{tabular}

There are differences in the average group values of a pair of the studied indicators in favor of the group of larger grain-sowing companies. These differences are found between the aggregates of companies on the basis of which the analysis of the influence of intensification level on the yield of grain crops was carried out.

\section{Conclusion}

The research showed that the size of the planted crops and the level of intensification have a significant influence on the change in yield. The following statistical methods were used as a quantitative analysis tool: correlation analysis, regression model and grouping, which have shown their practical effectiveness in the solution of the scientific problem and expediency in further research. The size factor of the grain sowing company has a very close stochastic relationship with the yield, which is qualitatively described by the parabolic model. The lowest yield indicators were found in the group of small agricultural companies. The yield increases with the enlargement of grain crops. The top point of the yield corresponds to the group of grainsowing companies with an area of crops from 5 to 10 thousand hectares. Then, a decrease in productivity begins to occur in the group of the largest agricultural companies. The influence of the intensification on productivity was assessed taking into account the elimination of the effect of size factor of the agricultural company. Therefore, the data were analyzed within the combined set of subjects: a group of large grain-sowing companies with an area of grain crops from 4 to 11 thousand hectares and medium-sized ones with an area of grain crops from 2 to 4 thousand hectares. In both cases, we found a pattern that a higher level of production costs per 1 hectare of grain crops provided a correspondingly higher yield (with a certain clarification for a group of large grain-sowing companies). The evaluation of the elasticity of the influence of production costs as a regressor on productivity showed that in large grain-sowing companies the indicator was relatively high and significantly higher than in the group of companies with medium-sized areas of grain crops.

\section{References}

1. A.A. Golovin, A.A. Golovin, T.V. Dobrinova, M.A. Parkhomchuk, K.A. Chebotareva Proceedings of the 35th International Business Information Management Association Conference, Spain Seville, 12192-12202.

2. D. Zyukin, O. Svyatova, E. Zolotareva, A. Bystritskaya, A. Alyokhina Amazonia Investiga, 9(25), 461-470, (2020)

3. D.A. Zyukin, O.N. Pronskaya, A.A. Golovin, T.V. Belova Amazonia Investiga, 28, 346-355, (2020)

4. A.I. Altukhov Bulletin of Kursk State Agricultural Academy, 5, 146-152, (2018)

5. S.R. Araujo-Enciso, T. Fellmann, Journal of agricultural economics, 2(71), 493-516, (2020).

6. A.I. Altukhov, A.A. Zavalin, N.Z. Milashchenko, S.V. Trushkin, Bulletin of Kursk State Agricultural Academy, 2, 32-39, (2020). 